\title{
Letters
}

Website: www.bmj.com

Email: letters@bmj.com

\section{How the cycle of poverty and ill health can be broken}

EDITOR-To paraphrase a well known remark-wars are too serious to be entrusted to generals-public health, especially among poor people in developing countries and in the inner cities of industrialised countries, is too serious to be left to doctors and nurses alone.

We say this quite deliberately as medical doctors on the staff of the World Health Organisation, of the Maryland department of health and mental hygiene, of universities, and of non-governmental organisations in Britain, Colombia, and Kenya. Our conviction is based on many years of work in the field in Africa, Asia, and Latin America, as well as in inner cities of the developed countries of Europe and North America. The number one health problem is poverty. For the poorest countries, the health sector alone cannot ensure better health even if it were able to function at maximum effectiveness. We have to accept that we can no longer deal with health while ignoring poverty.

The World Health Organisation's annual report on the state of the world's health asserted in 1995 that poverty is the main reason why babies are not vaccinated, why clean water and adequate sanitation are not available to hundreds of millions of people, why curative drugs and treatments are not

\footnotetext{
Advice to authors

We prefer to receive all responses electronically, sent either directly to our website or to the editorial office as email or on a disk. Processing your letter will be delayed unless it arrives in an electronic form.

We are now posting all direct submissions to our website within 72 hours of receipt and our intention is to post all other electronic submissions there as well. All responses will be eligible for publication in the paper journal.

Responses should be under 400 words and relate to articles published in the preceding month. They should include $\leqslant 5$ references, in the Vancouver style, including one to the BMJ article to which they relate. We welcome illustrations.

Please supply each author's current appointment and full address, and a phone or fax number or email address for the corresponding author. We ask authors to declare any conflicts of interest.

Letters will be edited and may be shortened.

www.bmj.com

letters@bmj.com
}

accessible, and why more than 500000 mothers die every year-unnecessarilyduring childbirth. It is also the underlying cause of reduced life expectancy.

The number of people living in absolute poverty-earning less than $\$ 370$ a year-has more than doubled since 1975 and now stands at 1.3 billion. Seven out of 10 of these are women. One need not point only to a developing country in the South to quantify the effects of poverty on people's health. Take Scotland in the North. The inhabitants of the huge housing development in suburban Drumchapel live close to Glasgow's richest suburb of Bearsden, but they die on average 10 years earlier than their wealthy neighbours.

The world is facing a health crisis that endangers the immense achievements of the past three decades. The situation is so bad and unfair that one can understand why it engenders discouragement and cynicism. There are many who are ready to write off classes of people, neighbourhoods, whole countries, and even continents. We are not among them.

We are convinced that a new approachnot the traditional, purely medical one-can go a long way, rapidly, towards improving the health of hundreds of millions of fellow humans. For what we see today is not new or unprecedented. The problems of developing countries and of inner cities in the North resemble those of large industrial cities in Britain and the United States in the 19th and early 20th centuries. The main causes of infant mortality at that time were the same as those affecting the poorest countries and peoples today. The squalid conditions in which working people lived and toiled changed dramatically for the better under the combined influence of clean drinking water, better sanitation and hygiene, female education, access to food, higher wages, and labour legislation. Doctors and health professionals could not, and did not, do it alone.

We all know the causes of spreading ill health, but can we actually do anything about them? Basic health care and basic education for all are vital, and investment for development must ensure that the poorest and most vulnerable groups of the population have access to them. This means giving priority to funding the healthcare system at community and district levels. Over the past two or three years the rich countries have reduced their development aid to developing countries.
This has resulted in less money for health precisely when more money is needed.

Our experience in the past 10 or 15 years on several continents shows that marginalising the poor while carrying out projects in their name is bound to fail. Poor people do not want gifts or handouts, they want opportunities. If we are honest enough to admit this, our ways of thinking and of operating will be radically different. Development from the bottom upwards with the active participation of poor people has proved to be the best and most sustainable approach.

Health must not be marginalised in a debate about the cost effectiveness of the health sector. Peoples and their leaders must now be reminded that health is the responsibility of society as a whole and not merely that of the medical establishment. To put it simply, there will be no lasting prosperity for the people of any country if public health is looked on as a secondary beneficiary of economic prosperity.

Rodrigo Guerrero Professor

School of Public Health, Universidad del Valle, Cali, Colombia

Michel Jancloes Director

John D Martin Associate director

Division of Intensified Cooperation with Countries and Peoples in Greatest Need, World Health

Organisation, 1211 Geneva 27, Switzerland

Andrew Haines Professor of primary care

Royal Free and University College London Schools of Medicine, London NW3 2PF

Dan Kaseje General director

Community Initiatives Support Services International, Nairobi, Kenya

Martin P Wasserman Secretary

Department of Health and Mental Hygiene,

Baltimore, Maryland 21201, United States

\section{Doctors can do something about poverty}

EDITOR-The attitudes of doctors to poverty matter. In their individual behaviour and in the work of their medical associations, doctors can either contribute to the health of the poor or help to undermine it. This was the message of an international meeting in December in London on poverty and health, the fourth in a series that has already produced the London declaration on poverty and health and the Baltimore charter on partnership for a healthy urban future. ${ }^{1}$ The latest meeting was about how to turn the rhetoric of these statements into action.

As the World Bank has coerced governments to reduce investment in state health sectors in the name of structural readjustment, so inadequately paid doctors and 
frightened, dissatisfied patients have been driven into the private sector. This has damaged the health of the poor and created a sense that doctors are withdrawing from the care of those whom society excludes. Increasingly, doctors seem to be driven by strategic self interest rather than the elusive goal of "Health for All." Doctors are also implicated in the rising tide of medicalisation, which defines quality in health care as more specialist, more technological, more invasive, and more expensive. The overprovision of health care in some settings drives the desperate underprovision elsewhere.

Medical associations have the power to influence debate and the responsibility to move beyond lobbying for vested interests and to deal with the wider determinants of health. Present at the December meeting were members of the newly formed UK Inter-Collegiate Forum on Poverty and Health, whose aim is to increase awareness and promote effective policies to reduce poverty and its adverse consequences on health. Medical associations in the developed world need to be aware of the ravages of the multinational pharmaceutical and tobacco industries across the developing world. Associations also exert powerful influence through their journals: with increasingly easy access via the internet, journals from the developed world are widely read in the developing world and have an impact on the discussion of issues. This places a responsibility on editors to be aware of the risks of seduction by healthcare technology.

At local level doctors must learn to value the knowledge and skills of poor communities themselves. Here, the developed world has much to learn from the work of community based non-governmental organisations in the developing world. In India as long ago as 1981, doctors and social scientists resolved to mobilise the poor and underprivileged to fight for their basic rights. ${ }^{2}$ Also in India illiterate women have proved themselves able to run effective immunisation programmes. Why is there nothing equivalent in Britain? Part of the answer lies in the diversity within poverty. In poor Asian and African countries strong communities have a huge potential to improve the health of their members, ${ }^{3}$ whereas in developed countries the poor and marginalised belong to much more fragmented, feebler communities. In the developing world, agencies have proved capable of providing services that are responsive to local needs. But to be fully effective non-governmental organisations need support from governments that provide a national framework of services which promote geographical and socioeconomic equity.

Links between poor communities and academic centres have enormous potential. In research, we need to find methods of exploring the close inter-relationship between poverty and ill health. Poverty, its causes, and its inter-relationship with ill health need to be included in medical school curriculums, which should offer community field practice and community health development courses. ${ }^{4}$

If the cycle of poverty and ill health is to be broken, doctors must support access to health care as a universal human right. ${ }^{5}$ This can be achieved only if communities and governments are committed to paying for health care through systems that involve some form of collective (and inclusive) risk sharing.

Iona Heath Chairman, Inter-Collegiate Forum on Poverty and Health

Royal College of General Practitioners, London SW7 1PU

On behalf of all who attended the meeting on poverty and health on 15-16 December 1997.

1 Division of Intensified Cooperation with Countries. Povert and health. Geneva: WHO, 1997.

2 Indian Council of Social Sciences Research and Indian Council of Medical Research. Health for all. New Dehli: ICMR, 1981.

3 CISS International. Community initiative support services international. Nairobi: CISS International, 1997.

4 Narayan R, Narayan T, Tekur SP. Strategies for social relevance and community orientation in medical education. Bangalore: Community Health Cell, 1993

5 Berwick D, Hiatt $\mathrm{H}$ Janeway P Smith R. An ethical code fo everybody in health care. BMJ 1997;315:1633-4.

\section{Developed countries could pay for hepatitis $B$ vaccination in developing countries}

EDIToR-The debate about the most cost effective policy for vaccination against hepatitis B in the United Kingdom has centred on the relative merits of selective and universal vaccination. ${ }^{12}$ A more imaginative approach is worth consideration.

The current incidence of acute hepatitis B in the United Kingdom suggests that the lifetime risk of acquiring infection is $0.4 \%$ (excepting perinatal transmission, which is controllable by well implemented antenatal screening) (Public Health Laboratory Service, unpublished paper). If $6 \%$ of infected people are assumed to develop chronic carriage, the lifetime risk of carriage is roughly 1 in 4000 ; universal vaccination would need to protect 4000 individuals to prevent one carrier.

An infant dose of vaccine against hepatitis $\mathrm{B}$ virus costs about $\$ 0.75$ in the poorest countries, compared with $£ 9(\$ 15)$ in the United Kingdom. If administration costs scale equivalently, the resources required to prevent one carrier in the United Kingdom would enable $80000(4000 \times 15 / 0.75)$ infants to be vaccinated in a developing country, thereby preventing 4000 people from becoming carriers (assuming the prevalence of carriage is $5 \%$ ). A vaccination programme would have clear benefits for that country and might also reduce the burden of chronic hepatitis B in the United Kingdom. For example, over 105000 United Kingdom residents were born in Bangladesh ${ }^{3}$ (population 110 million $^{4}$ ), which suggests that over recent decades roughly 1 in 1000 people born in Bangladesh has emigrated to the United Kingdom. At this level of immigration and assuming 5\% carriage in Bangladesh, the resources needed to prevent one carrier through universal vaccination in the United
Kingdom could prevent 4000 carriers in Bangladesh, of whom four might be expected to emigrate to the United Kingdom. This suggests that it would be four times more cost effective for the United Kingdom to sponsor a vaccination programme against hepatitis $B$ virus in Bangladesh than to introduce its own universal programme.

The global burden of hepatitis B could be reduced more cost effectively if vaccination was targeted at highly endemic areas. Many highly endemic countries, however, do not have the resources to introduce vaccination. In countries with a low incidence of infection, a high proportion of carriers are from highly endemic areas. The most cost effective approach for countries with a low prevalence to reduce their burden of chronic hepatitis B might be to sponsor vaccination programmes in developing countries. Since future migration patterns are impossible to predict, this would require global coordination to enable all highly endemic countries to introduce universal vaccination against hepatitis $B$ virus, to the benefit of both the developed and developing world.

N J Gay Principal scientist

Immunisation Division, Public Health Laboratory Service Communicable Disease Surveillance Centre, London NW9 5EQ

W J Edmunds Research fellow

Department of Biological Sciences, University of Warwick, Coventry CV4 7AL

1 Van Damme P, Kane M, Meheus A. Integration of hepatitis $B$ vaccination into national immunisation programmes. BMJ 1997;314:1033-6.

Mortimer PP, Miller E. Commentary: antenatal screenin and targeting should be sufficient in some countries. $B M$ 1997;314:1036-7.

Office of Population Censuses and Surveys, General Register Office for Scotland. 1991 Census: ethnic group and country of birth, Great Britain. London: HMSO, 1993.

4 United Nations. 1995 demographic yearbook. New York: UN,

\section{Africa needs leadership by Africans of high calibre}

EDitor-Logie et al have produced a thought provoking paper on African hopes for the 21 st century. ${ }^{1}$ They point out many causes for Africa's underdevelopment and "retrodevelopment"-among them the colonial legacy, World Bank policies, dwindling and "yo-yoing" aid (which returns to its source almost as quickly as it is given), the brain drain, and the role of industrialised nations and multinational companies in the destabilisation of Africa.

In its emphasis on what the West is doing to Africa, however, rather than what Africa is doing to itself, the paper falls slightly short. ${ }^{23}$ It is only when this aspect of the problem is faced squarely that African dependency can be reduced. Weak corrupt governments lacking commitment cannot stand up to the World Bank and the multinational companies. ${ }^{4}$ Even if $\$ 100$ billion were pumped into Africa tomorrow, without the necessary protocols, safeguards, and leadership the cycle of debt would soon start spiralling again because of borrowing by the new elite and skewed priorities. 
Many of Africa's poor nations have hundreds of development goals and targets; many of these remain aspirational. Yet many of Africa's poorest nations are blessed with an abundance of natural resources. Unless the leadership deficit in Africa is addressed the United Nations' special initiatives will join a containerful of hopes and aspirations for Africa that never get implemented. ${ }^{5}$ Africa needs leadership of a high calibre: leaders who will facilitate national and grassroots development. Many doctors have influential roles in many governments and non-government organisations.

John Lwanda General practitioner

Airdrie Health Centre, Airdrie ML6 0SU

1 Logie DE, Benatar SR. Africa in the 21st century: can despair be turned to hope? BMJ 1997;315:1444-6. (29 November.)

2 Sachs W, ed. The development dictionary: a guide to knowledge as power. London: Zed Books, 1992.

3 Lwanda JL. Promises, power politics and poverty: the democratic Lwanda JL. Promises, power politics and poverty: the democratic
transition in Malawi, 1961-1999. Glagow: Dudu Nsomba,

4 Ellis S, ed. Africa now: people, policies, institutions. Portsmouth: Heinemann, 1996

5 Werbner R, Terence R, eds. Postcolomial identities in Africa. London: Zed Books, 1996.

\section{Improved bacteriological data are needed to give uniform reporting of tuberculosis in Europe}

EDITOR-Comparative assessment of the incidence of tuberculosis in Europe has been hampered by differences in national "EuroTB" was initiated. It was based on three

- a case definition of notifiable tuberculosis encompassing both definite and nondefinite diagnosis and the specification that, whenever possible, a definite diagnosis should be confirmed by culture;

- a system based on individual notification by both the clinician and the laboratory;

- the collection of computerised information with a minimum set of variables.

Baseline data on cases of tuberculosis notified in 1995 in the 50 countries of the World Health Organisation's European region were requested. ${ }^{4}$ Forty six countries have provided information; the table summarises the results from the 18 with individual information on pulmonary tuberculosis. In the six countries requiring a positive culture to classify a case as definite (group A), a total of 1902 cases of pulmonary tuberculosis were surveillance systems. ${ }^{12}$ In 1996 the project recommendations ${ }^{3}$ : computerised data including bacteriological

notified, $1536(81 \%)$ of which were positive on culture $(34 \%$ with a positive sputum smear, $47 \%$ without). Five per cent of the cases were reported as smear positive without confirmation by culture. In the 12 other countries (group B) accepting culture positivity or sputum smear positivity, or both, $64 \%$ of the 50329 cases of pulmonary tuberculosis were reported as positive: $24 \%$ by both examinations, $17 \%$ by culture only, and $23 \%$ by smear only. Almost half of the smear positive cases had no confirmation by culture mostly because results of culture were unknown. Apart from providing a presumptive diagnosis of tuberculosis, sputum smear positivity is an excellent predictor of infectiousness. ${ }^{5}$ To validate the reporting of cases, however, information on culture is essential. Culture is both more sensitive than a smear test for diagnosing tuberculosis and more specific, since false positive smears may be due to environmental mycobacteria. In the 18 countries with individual computerised data, culture is performed routinely. Results of culture results seemed to be largely underreported except in the six countries requiring culture positivity for classifying a case as definite. The insufficient completeness of information on both culture and smear testing probably reflects the little emphasis placed on the reporting of bacteriological data. Inclusion of high quality bacteriological information in national tuberculosis surveillance is best achieved by incorporating laboratories into the notification scheme, as is now recommended. ${ }^{3}$ This would not only improve case finding but also form the basis of surveillance of resistance to antituberculosis drugs and substantiate the monitoring of the outcome of treatment. The EuroTB project will continue its efforts in 1998.

EuroTB receives financial support from the Commission of the European Communities (Directorate General V).

Valerie Schwoebel Medical epidemiologist European Centre for the Epidemiological Monitoring of AIDS, Saint-Maurice, France

Anne Perrocheau Medical epidemiologist Reseau National de Sante Publique, Saint Maurice, France

Jaap Veen Tuberculosis control consultant Royal Netherlands Tuberculosis Association, Postbus 146, 2501 CC The Hague, Netherlands

Hans L Rieder Chief, tuberculosis section International Union Against Tuberculosis and Lung Disease, 75006 Paris, France

Mario C Raviglione Chief, surveillance and epidemiology unit

Global Tuberculosis Programme, World Health Organisation 1211 Geneva 27, Switzerland

Bacteriological information on cases of pulmonary tuberculosis in 18 European countries with individual computerised data, 1995. Figures are numbers (percentages)

\begin{tabular}{llcr} 
Bacteriological status & Group $\mathbf{A}^{*}$ & \multicolumn{1}{c}{ Group B† } & \multicolumn{1}{c}{ Total } \\
\hline Culture positive and smear positive & $640(34)$ & $12190(24)$ & $12830(25)$ \\
\hline Culture positive but smear negative/result unknown/smear not done & $896(47)$ & $8526(17)$ & $9422(18)$ \\
\hline Culture negative/result unknown/culture not done; smear positive & $101(5)$ & $11409(23)$ & $11510(22)$ \\
\hline Culture negative and smear negative/result unknown/smear not done & $265(14)$ & $18204(36)$ & $18469(35)$ \\
\hline Total & $1902(100)$ & $50329(100)$ & $52231(100)$ \\
\hline
\end{tabular}

*Denmark, Finland, Iceland, Norway, Sweden, Switzerland.

†Austria, Belgium, Bosnia-Herzegovina, Estonia, France, Italy, Luxembourg, Malta, Netherlands, Poland, Romania, Slovenia.
1 Raviglione M, Sudre P, Rieder HL, Spinaci S, Kochi A. Secular trends of tuberculosis in western Europe. Bull World Health Organ 1993;71:297-306.

2 Raviglione MC, Rieder HL, Styblo K, Khomenko AG, Esteves K, Kochi A. Tuberculosis trends in eastern Europe and the former USSR. Tuberc Lung Dis 1994;75:400-16.

3 Rieder HL, Watson JM, Raviglione MC, Forssbohm M, Migliori GB, Schwoebel V, et al. Surveillance of tuberculosis in Europe. Recommendations of a working group of the World Health Organization (WHO) and the European region of the International Union Against Tuberculosis and Lung Disease (IUATLD) for uniform reporting on and Lung Disease (IUATLD) for uniform report

4 tuberculosis cases. Eur Respir 1996;9:1097-104. Perrocheau A, Schwoebel V, Veen J, national co-ordinators for tuberculosis surveillance in 46 countries of the WHO European region. Surveillance of tuberculosis in the WHO European region in 1995: results of the feasibility study.

5 Shaw JB, Wynn-Williams N. Infectivity of pulmonary tuberculosis in relation to sputum status. Am Rev Tuber $1954 ; 69: 724-32$

\section{An ethical code for everybody in health care}

\section{The role and limitations of such a code} need to be recognised

EDITOR-Ethics are not optional in medicine: they are an essential and integral part of health care. A common ethical code for everybody involved in health care, as proposed by Berwick et al, ${ }^{1}$ is potentially valuable and is to be welcomed, but the role and limitations of such a code need to be recognised.

An ethical code cannot provide the answer to specific ethical problems. Rather than dictating particular actions a code should describe the ethical environment for the delivery of health care and reflect its character and general approach. An ethical code should not try to make subjective aspects of care more objective or separate value from practical situations: it is in the nature of the work of professions that there remains individual responsibility for ethical practice. If challenged, ethical codes cannot explain why moral judgments should be made or give a firm justification for making those judgments; considered, individual moral judgments themselves are more basic and require no more profound reference.

Ethical codes can give shape and structure to our moral environment and summarise our ethical position while leaving ethical responsibility with the individual practitioner. Looked at in this way, individual variation and personal issues can be taken into account. An ethical code can facilitate the discussion of ethical issues in difficult cases, and distinctive ethical positions can be established and argued, leading to broader and more secure moral conclusions. An ethical code can describe the ethical attitudes that are shared by healthcare workers, and in this it can be immensely valuable and influential. But what it cannot do is provide the certain answers for the many ethical problems encountered in the course of medical practice.

Alexander E Limentani Director of health policy and public health

East Kent Health Authority, Protea House, Dover, Kent CT17 9BW

1 Berwick D, Hiatt H, Janeway P, Smith R. An ethical code for everybody in health care. BMJ 1997;315:1633-4. (2027 December.) 


\section{Three crucial limitations need to be considered}

EDITOR-The call by Berwick et al for the development of a new ethical code for everybody in health care raises a few crucial practical issues. ${ }^{1}$

The first is that a simple ethical code capable of providing the answers to all ethical dilemmas, both present and future, has been sought in vain since Greek times. The confounding factor is still that it is impossible to predict all possible future circumstances and to construct a code to cater for them. If this is what the authors seek they will also fail.

The second practical issue is that of gaining consensus among all the different groups within health care. The wider the scope of the intended code the less specific it can be. Compromises will have to be made and wording modified in order to satisfy all the groups. This process can only lead to a code whose agreed text, no matter how long, will be too general to be of use in many specific cases.

Of course, if the authors want their code to be used and remembered it will have to be short. If it is to be short it will have to be general since there will not be space for details. Thus the most that can be achieved is something like a heavily revised Hippocratic Oath (the BMA's recent attempt ${ }^{2}$ is still only for doctors) or, in modern jargon, an international mission statement for health care: something very general and quite useless next time I have a specific problem to resolve.

Still, if its limitations are accepted the development of a new code might be useful. If the process makes more people reflect on ethical issues, that will be more useful than the end product itself. This then leads on to the third practical issue: who will be involved in developing the code? It should be everyone, not just the cognoscenti.

Saul Miller Scottish higher training fellow in general practice

Belford Medical Practice, Belford, Northumberland NE70 7ER

1 Berwick D, Hiatt H, Janeway P, Smith R. An ethical code for everybody in health care. BMJ 1997;315:1633-4. (2027 December.)

2 BMA. Draft revision of the Hippocratic Oath. In: Аппиа report of council 1996-7. London: BMA, 1997:26.

Patients should help to shape such a code EDITOR-I was delighted by the proposal of Berwick et al of an ethical code to cover everybody rather than single groups in health care. ${ }^{1}$ I have thought for sometime that an examination of the values base in health care, followed by the beginnings of the formulation of such a widely held code of ethics, is now an urgent task on our agenda. The King's Fund, in partnership with others, is proposing to work on values in the NHS during its 50th anniversary to stimulate debate.

But, given the stated desire of all healthcare professionals to protect patients and the argument of Berwick et al that such a code should unify all those "who shape the experience of patients and the social investment in care," it seems extraordinary that patients and users of services do not figure among those who are to help to shape such a code. Without active patient and user participation, this exercise, albeit very welcome, runs the risk of being overly academic and yet again being a code for those who are licensing themselves to do things to other people rather than work in participation with them.

Julia Neuberger

Chief executive, King's Fund, London WIM OAN

1 Berwick D, Hiatt H,Janeway P, Smith R. An ethical code for everybody in health care. BMJ 1997;315:1633-4. (2027 December.)

\section{A universal declaration of patients' rights} is a complementary approach

EDITOR-An ethical code for everybody in health care is a laudable goal, ${ }^{1}$ but it addresses only one aspect of the health care problem. A professional code of ethics that establishes worldwide obligations of healthcare providers continues to place protection of patients in the hands of the professionals. An alternative and complementary approach is the development of a universa declaration of patients' rights. Global Lawyers and Physicians, a transnational health and human rights organisation, has adopted this as one of its major goals. A human rights approach to patients centres on their shared humanity and dignity and derives the obligations of providers from their relationship to patients. See our web page (www-busph.bu.edu / Depts / LW / GLPHR HTM) for details.

George J Annas Professor of health law Michael A Grodin Professor of medical ethic Global Lawyers and Physicians, Boston University School of Public Health, 715 Albany Street, Boston, MA 02118, USA

Berwick D, Hiatt H, Janeway P, Smith R. An ethical code for
everybody in health care. BMJ 1997;315:1633-4. (2027 December.)

The code should follow the moral principles of law abiding citizens

EDITOR-Berwick et al discussed the idea of an ethical code for everyone in health care. The lack of a stated ethical code with clear basic guiding principles is the main cause of difficulties facing doctors in resolving ethical conflicts in medicine. Furthermore, the failure to apply such codes to planned policies and actions often causes such conflicts to arise.

A code should follow the moral principles which a country's government expects its law abiding citizens to observe, some being ideals not achievable by all but others being legally binding and carrying a legal penalty. The right to freedom of speech and opinion is fundamental and must extend to the professional opinions and working conditions of medical staff. To maintain public trust, the facts of any issue must be available for scrutiny, unless there are overriding rights to personal privacy.

Here the nationally accepted codes are Judaeo-Christian in origin. Some will prefer to describe them as humanitarian. Medical situations have traditionally been governed by the pronouncements of Hippocrates. For other nations, religions, and cultures the basic general standards may vary as appropriate, but the Hippocratic Code should remain the foundation for the ideal to be observed by the medical professions.

An international statement of human rights already exists. Underpinning international laws, there could be an ethical code governing the ideal behaviour that a government might expect from its citizens. The next step would be a world code of medical ethics and ideals for all health professionals.

Some 40 years ago my non-medical father, a social security civil servant, decided the final appeal settlements of all disputed benefit claims in Scotland. I recall remarking that without formal qualification in medical and legal matters he must find it difficult to make acceptable judgments. However, his department had given him two final criteria to be satisfied in all disputes: decisions had to be truthful and fair but they had also to be clearly seen by ordinary citizens as being so. Fulfilling these two criteria had greatly simplified his task of arbitration. Such concepts seem to be in short supply nowadays.

In summary, an ethical code for medical professionals should:

- Conform with the accepted codes and standards of behaviour for the country concerned

- Conform with a new international standard

- Incorporate the principles of Hippocrates

- Encapsulate the rights of free speech and freedom of opinion

- Insist on truth in resolving ethical difficulties

- Reflect fairness to the ordinary citizen in its solutions to problems.

M F Brewster Retired general practitioner Wigtown, Wigtownshire DG8 9DZ

1 Berwick D, Hiatt H, Janeway P, Smith R. An ethical code for everybody in health care. BMJ 1997;315:1633-4. (2027 December.)

\section{A universal code should start with basic human rights}

EDITOR-Berwick et al invited readers of the $B M J$ to express their views about a code of ethics for all. ${ }^{1}$ Given the increasingly complex ethical issues raised by emerging medical developments, we believe such a code would be widely welcomed by all those concerned with making decisions about health care.

We suggest a universal code of ethics should first consider basic human rights because such rights cut across political and cultural boundaries and would therefore be acceptable to international organisations such as the World Health Organisation. We would define these as fundamental human rights necessary for successful existence in human society. If Maslow's hierarchy of needs ${ }^{2}$ are adapted to consider human rights, people have basic rights to physi- 
ological requirements (healthy food, warmth, shelter, clean air, clean water, sanitation, and others), to security needs (protection from physical and mental abuse), and to social needs (education, support through the growing years, a social framework, adequate health care, and others). Maslow's higher needs of a desire for self esteem and self fulfilment, though important to the individual person, cannot be deemed basic human rights.

The right to health care (social need), the right of the unborn child to life (physiological), the right to be properly informed (social), and the right to be protected from abuses of treatment or research are best defined as human rights. However, the so called rights to cosmetic surgery, to have a child, and to clone a dead relative cease to be classed as basic human rights and are best classed as a desire for self fulfilment.

We recognise the limitations of this approach when we try to refine the right to life and introduce the concept of brain stem death or fetal viability. We also accept that in the future it will be possible to modify the individual's genetic potential, and this may be translated into a right to receive gene therapy when appropriate.

Society through its organisations has duties and responsibilities to all its residents, and these also need to be defined. Berwick et al cite examples where conflicts arise between the organisation's responsibilities and the individual person's rights. ${ }^{1}$

A well informed public needs to determine what resources and which powers it wishes to allocate to its health service and health authorities. This requires an effective democratic process to be in place with proper accountability, which is woefully inadequate in many parts of the world.

Stephen Hyer Consultant physician

Hervey Wilcox Consultant chemical pathologist Diabetes Centre, St Helier Hospital, Carshalton, Surrey SM5 1AA

1 Berwick D, Hiatt H, Janeway P, Smith R. An ethical code for everybody in health care. BMJ 1997;315:1633-4. (2027 December:

2 Maslow A. Motivation and personality. New York: Harper and Row, 1954

\section{The healer's promise}

EDITOR-We of the National Federation of Spiritual Healers have developed a healer's promise, which I think is a suitable contribution towards an ethical code for everybody in health care, as discussed by Berwick et al. ${ }^{1}$ Healers are the largest non-statutory complementary group of practitioners in the United Kingdom. ${ }^{2}$ The federation accounts for $60 \%$ of all healers, and over the past year it has been reviewing the basis of its code of conduct. All members were invited to respond in writing with their vision of a better world and the values that underlie such a vision. We had 300 replies, or a $5 \%$ response. Reviewing the established code of conduct and the postal replies, we were able to form a good idea of the qualities that members past and present thought were important. At the council conference, with representatives from all 14 regions participating, a working group discussed how these values could be communicated to healers and the general public and a healer's promise was created.

\section{The Healer's Promise}

All who come to me for healing I will treat with compassion,

Regardless of colour, creed, or race.

My attitude will be non-judgmental and caring.

I shall be honest in my dealings,

And all that is said to me shall be confidential

I will act with integrity and kindness.

I shall consider my own wellbeing to be important,

And I will endeavour to be true to myself. I will attune with the source of Peace and Love.

Craig K Brown General practitioner

Rustington, West Sussex BN16 3NX

1 Berwick D, Hiatt H, Janeway P, Smith R. An ethical code for everybody in health care. BMJ 1997;315:1633-4. (20everybody in

2 Mills S, Peacock W. Professional organisation of complementary and alternative medicine in the United Kingdom. A report to the Department of Health. Exeter: Centre for Complementary Health Studies, University of Exeter, 1997.

\section{Hippocratic Oath translated into poetry}

EDITOR-Berwick et al suggested that an ethical code for all those in health care would be timely and orienting and asked who could create it and how it could be implemented and become alive. ${ }^{1}$ Hurwitz and Richardson also discussed the resurgence in medical oaths, noted that the Hippocratic Oath is being re-examined afresh for moral guidance, and included the BMA's draft revision. ${ }^{2}$ We think that this draft reads more as a mission statement, is too detailed, very difficult to learn, and will have little unifying effect among all of us working in health care. Instead, we support Dr Mark Porter, member of BMA council, who suggested that "an oath to be taken by millions of doctors over decades needs to be translated into poetry as a ringing declaration of principle" and that a poet should be commissioned to produce a better version. The Observer commissioned one of us (DH) to do this. ${ }^{4}$ We are grateful for permission to reproduce it with minor amendments to encompass all of us working in health care. We hope it will resonate in the heart of anyone who reads or recites it.

\section{Swear By The Music}

I swear by the music of the expanding universe and by the eloquence of the good in all of us that I will excite the sick and the well by the severity of my kindness

to a wholeness of purpose. I shall apply my knowledge,

curiosity, ignorance and ability to listen.

I shall cooperate with wondering practitioners in the arts and the sciences,

with all who care for people's bodies and souls, so that the whole person in relationship shall be kept in view, their aspirations and their unease.

The secrets of the universal mind

I shall try to unravel to yield beauty and truth.

The fearful and sublime secrets told to me in confidence

I shall keep safe in my own heart.

I will not knowingly do harm to those in my care, I will smile at them and encourage them to attend to their dreams and so hear the voices of their inner strangers.

If I keep to this oath I shall hope for the respect of my teachers,

and of those in my care and of the community, and to be healed even as I am able to heal.

Robin Philipp Consultant occupational physician Bristol Royal Infirmary, Bristol BS2 8HW

David Hart Freelance writer and poet Birmingham B14 7LL

1 Berwick D, Hiatt H, Janeway P, Smith R. An ethical code for everybody in health care. BMJ 1997;315:1633-4. (2027 December.

2 Hurwitz B, Richardson R. Swearing to care: the resurgence in medical oaths. BMJ 1997;315:1671-4. (20-27 December.) 3 BMA's annual representative meeting. Doctors want Hippocratic oath revised. BMJ 1997;315:130.

4 Hart D. I swear by the music. Observer 1997 July 6 .

\section{Accidental child poisoning}

\section{Child resistant packaging should be used} on all over the counter drugs

EDITOR-Although the mortality from accidental poisoning among children is low, it is none the less an important cause of presentation to accident and emergency departments in the United Kingdom. ${ }^{1}$ Accidental child poisoning is a potentially preventable situation that causes concern to both parents and medical staff, and appreciable numbers of children require admission to hospital. During December 1997 we treated 35 cases of accidental poisoning in children in our paediatric accident and emergency department. The substances that the children ingested are shown in the table.

Tixylix Night-time was the most commonly ingested substance, and cough or cold mixtures in total constituted $26 \%$ $(9 / 35)$ of the poisonings for the month. Of these nine cases, six were boys; eight of the cases were aged between 18 months and 5 years. Two children were admitted to hospital: one because of drowsiness and confusion, and one because of persistent dizziness. None of the preparations ingested had been in a child resistant container.

Substances ingested by 35 children treated for accidental poisoning during December 1997

\begin{tabular}{ll} 
Substance & No of cases \\
\hline Tixylix Night-time & 7 \\
\hline Paracetamol & 5 \\
\hline Karvol & 4 \\
\hline Vitamin pills & 4 \\
\hline Other cough mixtures & 2 \\
\hline Industrial cleaner & 2 \\
\hline Temazepam & 2 \\
\hline Thyroxine & 1 \\
\hline Bleach & 1 \\
\hline Amphetamines & 1 \\
\hline Methadone & 1 \\
\hline Essential oil & 1 \\
\hline Oral contraceptives & 1 \\
\hline Sewing machine oil & 1 \\
\hline Aftershave & 1 \\
\hline Sudafed tablets & 1 \\
\hline
\end{tabular}


In the previous two months no cases of accidental poisoning with Tixylix were seen in the department and we believe that the relatively high numbers seen in December reflect the product's availability in the home at this time of year-the coughing season. (This coincided with the bronchiolitis season in Edinburgh.) Tixylix Night-time contains $1.5 \mathrm{mg}$ promethazine and $1.5 \mathrm{mg}$ pholcodine in each $5 \mathrm{ml}$ dose. The fatal dose is unknown but common systemic features include flushing, dilated pupils, dry mouth, sinus tachycardia, ataxia, nystagmus, agitation, confusion, and visual hallucinations. Rarely, coma, convulsions, and dysrhythmias have been seen. The Edinburgh Poisons Unit (Toxbase) recommends gastric lavage if a large amount of Tixylix has been ingested in the previous 2 hours, administration of oral activated charcoal, and that the patient be observed for at least 4 hours.

In 1981 the British government and the pharmaceutical profession agreed voluntarily to place all solid dose, prescribable medications in either child resistant containers or blister packs, with exceptions to this packaging being made for elderly people or others who specifically request it.

Although child resistant containers have been shown to be effective in preventing accidental poisoning in children, ${ }^{2}$ there is no legislation requiring their use for over the counter cough preparations that do not contain aspirin or paracetamol, and the use of this packaging is at the professional discretion of the pharmacist.

We feel that these medications should be sold in child resistant containers to prevent poisonings in children.

John O'Donnell Specialist registrar in accident and emergency medicine

Fiona D Brown Research fellow

Thomas F Beattie Consultant in paediatric accident and emergency medicine

Accident and Emergency Department, Royal

Hospital for Sick Children, Edinburgh EH9 1LF

1 Sibert JR, Clarke AJ, Mitchell MP. Improvements in child resistant containers. Arch Dis Child 1985;60:1155-7.

2 Jackson RH, Craft AW. Poisoning and child resistant containers [letter]. BMJ 1992;305:529.

\section{Child resistant packaging should be legal} requirement

EDITOR-During the 12 months from January to December 1996, 13 children presented to our paediatric accident and emergency department after accidentally ingesting Tixylix syrup. This alerted us to the persistent problem of packaging potentially dangerous children's medicine. Of the 13 children seen in the department one was admitted, three received oral charcoal and were observed for six hours, one had blood taken for urea and electrolyte estimation, two were observed for four hours in the department, and six were examined and reassured. On each occasion advice on treatment was obtained from a regional poisons centre. During the same period a similar number of families were given telephone advice after children had accidentally ingested Tixylix at home.
There are six different Tixylix preparations available; each contains different active ingredients. None are sold in child resistant containers, and all are packaged and flavoured to appeal to children. Swallowing a bottle of Tixylix syrup containing guaiphenesin (an expectorant) may not pose a threat to a small child's health, but swallowing a bottle of the Tixylix product containing pseudoephedrine (a sympathomimetic) or diphenhydramine (an antihistamine) certainly could.

In 1994 the Royal Pharmaceutical Society of Great Britain reported that it hoped that beginning 1 January 1996 the pharmaceutical industry would use child resistant containers for all its liquid medicines. ${ }^{1}$ It seems that few pharmaceutical companies have complied with this voluntary deadline even though liquid medicines dispensed by pharmacists have been supplied in child resistant containers since 1995, and the dangers of accidental overdose from bottles without child resistant tops have been highlighted regularly. ${ }^{2-4}$

Legislation seems to be the only way to ensure that all liquid medicines from manufacturers are supplied in child resistant containers.

Glive Newman Senior pharmacist

Pharmacy Department, Queen's Medical Centre, University Hospital, Nottingham NG7 2UH

Stephanie Smith Consultant paediatrician Sharon Cotton Staff nurse

Department of Paediatric Accident and Emergency, Queen's Medical Centre

1 Odd RW. Child resistant containers. BMJ 1994;309:670-1. 2 Laing G, Thompson M, Logan S. Child resistant packaging and accidental child poisoning. Arch Dis Child 1994; and accic

3 Jacobs M. Child resistant containers needed for liquid medications. $B M J$ 1993;306:145.

4 Williams JM. Child-proof closures for liquid medicines. Pharm J 1992;248:732.

\section{Manufacturer's reply}

EDITOR-Thank you for the opportunity to respond to the two letters about accidental poisoning with our product Tixylix. We are grateful for this information as we like to obtain reports for pharmacovigilance monitoring.

The use of child resistant and tamper evident packaging has been the subject of much debate. We intend to move to packaging Tixylix in a child resistant container but we must emphasise that this is only one of a number of factors that must be observed if medicine is to be administered safely. While manufacturers must ensure that a medicine is safe and correctly labelled for proper use, it is equally important to remember that it is incumbent on parents or guardians to ensure that medicines are stored well out of the reach of children, preferably in a locked cabinet, and used correctly.

At any time after the age of 2 years, children can learn to open child resistant packaging. It is therefore important to reduce the hazard by minimising the child's exposure to the container. This is possible if adults refrain from opening and taking medicine in front of the child and if, when administer- ing the medicine to a child, the dose is measured out of the child's sight. Another common cause of the accidental misuse of a liquid medicine is the failure to firmly replace the cap after use.

Child resistant containers are clearly not the complete answer as misuse occurs with containers which are classed as child resistant. That this is true is supported by the table supplied by O'Donnell and colleagues which contains reports of accidental poisoning by medicine that is supplied in child resistant containers.

We are always concerned about receiving such complaints but remain convinced that the Tixylix range of medicine remains safe and effective when used correctly.

D S Kettle Director of regulatory and medical affairs Novartis Consumer Health, Horsham, West Sussex RH12 4AB

\section{Report on cleft lip and palate surgery}

\section{UK results could soon surpass those elsewhere}

EDITOR-As a plastic surgeon I welcome the report by the cleft lip and palate committee of the Clinical Standards Advisory Group. ${ }^{1}$ However, in her news article Bower and (in his comments) the dean of the faculty of dental surgery, Mr John Williams, have got it all wrong. ${ }^{2}$ The report is not about a confrontation over who should do cleft lip and palate surgery but about what is best for a baby, child, adolescent, and adult unfortunate enough to have been born with these deformities.

The report says clearly that what is best is a team with a full range of clinical skills that manage the patient for 20 years. The team consists of a plastic surgeon, oral and maxillofacial surgeon, nurses, speech therapist, orthodontist, and paediatrician, all properly trained and with agreed training pathways. If one accepts that the more operations you do the better you are then the report is correct in recommending a reduction in the number of teams to treat the 700 new cases a year. The disadvantage of this aim is the difficulty for parents and children travelling to the clinics in both rural and urban communities, as pointed out by Professor Roy Sanders. ${ }^{2}$ The report emphasises the need for records and proper audit over 20 years as it often takes that long for the outcome to be judged. There will be an implementation group to advise on the precise number and distribution of the teams and the need for comparative audit between the teams after a period of five years.

I must set the record right: the comparison of results in the report is between the average of the best and worst centres in the United Kingdom against the acknowledged four best centres on the continent. The results of secondary alveolar bone grafting by plastic or oral and maxillofacial surgeons showed no significant difference. If an unbi- 
ased implementation group sets up a limited number of adequately funded teams then our results in the United Kingdom could soon surpass those elsewhere.

B D G Morgan Consultant plastic and reconstructive surgeon

University College Hospital, London WC1E 6AU

1 Clinical Standards Advisory Group. Cleft lip and/or palate. London:HMSO, 1998

2 Bower H. Unpalatable results force cleft surgeons to rethink. BMJ 1998;316:723. (7 March.)

\section{Disagreement between specialties was not impetus for study}

EDITOR-The report on cleft lip and palate by the Clinical Standards Advisory Group is based on the results of the largest outcome study of patients with the condition ever undertaken in the United Kingdom. ${ }^{1}$ It confirms what many had feared-that the standard of care in the United Kingdom for patients with this condition is below that of northern Europe. The government has responded positively to the recommendations, and care for these patients is to be reorganised. The number of teams will be reduced from 57 to $8-15$.

We are concerned that Bower's article gives the impression that the impetus for this study was the disagreement over treatment for these patients between maxillofacial surgeons and plastic surgeons. ${ }^{2}$ Although the number of maxillofacial surgeons operating on primary clefts has increased recently and debate has arisen over which specialty is best suited to care for children with the condition, ${ }^{3}$ concerns about the standards of care in the United Kingdom were raised long before many of these new teams were established. The concerns were centred on the fact that care for patients with cleft lip and palate in the United Kingdom was based on low volume operators, whereas countries producing superior results (such as Norway) have centralised such care for many years. ${ }^{3}$ The advisory group's cleft lip and palate committee made every effort to move the study away from interspecialty differences to concentrate on the main issue - quality of care.

It was also stated that "limited recordkeeping meant that comparison could be drawn only in alveolar bone grafting." Lack of systematic record keeping meant that few existing records were available about any aspect of care; most of the outcome data were collected by the research team. It takes five years before the outcome of care of cleft lip and palate can be assessed objectively, ${ }^{4}$ and many of the maxillofacial surgeons who currently care for these patients had not been operating for long enough on a sufficient range of patients to contribute to the study. Although the results of bone grafting seem to indicate that maxillofacial surgeons achieved slightly better outcomes, the difference between the specialties was not significant and, more importantly, neither specialty obtained the $97 \%$ success rate achieved in Oslo. ${ }^{1}$

The study has shown that the outcome of care of cleft lip and palate in the United
Kingdom is generally poor, regardless of which specialty is involved. It is this that has led the government to recommend change.

Alison Williams MRC special training fellow Jonathan Sandy Reader in orthodontics CSAG Cleft Lip and Palate Research Team, Department of Child Dental Health, University of Bristol Dental Hospital, Bristol BR1 2LY

\section{Clinical Standards Advisory Group. Cleft lip and/or palate. London: HMSO, 1998. \\ 2 Bower H. Unpalatable results force cleft surgeons to rethink. BMJ 1998:316:723. (7 March) \\ 3 Shaw WC, Dahl E, Asher-McDade C, Brattstrom V, Mars M, McWilliams J, et al. A six centre international study of treatment outcome in patients with clefts of the lip and palate. Parts 1-5. Cleft Palate Craniofac J 1992;29:393-418. 4 Shaw WC, Dahl E, Asher-McDade C, Brattstrom V, Mar $\mathrm{M}, \mathrm{McWilliams} J$, et al. A six centre international study of treatment outcome in patients with clefts of the lip an palate. Parts 1-5. Cleft Palate Craniofac J 1992;29:393-418. \\ 5 Atack N, Hathorn I, Mars M, Sandy JR. Study models of 5 year old children as predictors of surgical outcome in uni- lateral cleft lip and palate. Eur J Orthod 1997:19:165-70.}

Surgeon's specialty is less important than training and experience

EDIToR-Bower's article about the Clinica Standards Advisory Group's findings on cleft lip and palate repair in the United Kingdom and the overall poor results is selective and misleading. ${ }^{1}$ It states that a key factor in these results noted by the committee was competition between plastic and maxillofacial surgeons. Indeed, the report comments that competition can be effective in raising standards. ${ }^{2}$ Fragmentation could, however, lead to impaired training and low volume operating, although the advisory group's committee failed to show a clear correlation between volume operating and outcomes.

Historically, general plastic surgeons carried out these operations, accounting for most of the poor results observed in the 277 children aged 12. Competition from maxillofacial surgeons with their specialist knowledge of the mouth, face, and jaw has focused attention on this congenital abnormality, which has driven standards up. Possession of additional basic and higher qualifications in dentistry is recognised by many, including plastic surgeons, ${ }^{3}$ as advantageous in the treatment of maxillofacial deformities such as cleft lip and palate. A joint meeting at the Royal College of Surgeons highlighted this viewpoint. Maxillofacial cleft surgeons, unlike plastic surgeons, provide a comprehensive service of primary and secondary cleft procedures from infancy to adult life.

I agree that the parent specialty of the cleft surgeon is less important than the training and experience of the surgeon. But training should include specialist knowledge of the mouth, jaws, and face acquired through formal training in dentistry; specialisation in surgery in the head and neck region; experience in all aspects of cleft surgical management; and a willingness to scrutinise personal results, participate in audit among centres, and correct inappropriate practices. In his defence Professor Roy Sanders states, in Bower's article, that plastic surgeons have been operating on cleft lips and palates for years. The problem is that they have been doing it badly as the reported results show.
It is essential for the advancement of cleft care in the United Kingdom that the advisory group's report is not devalued by misplaced and unfounded attempts to attribute the poor results of the past to competition and rivalry between the specialties.

Alistair G Smyth Consultant oral and maxillofacial surgeon

Middlesbrough General Hospital, Middlesbrough, Cleveland TS5 5AZ

1 Bower H. Unpalatable results forces cleft surgeons to rethink. BMJ 1998;316:723.

2 Clinical Standards Advisory Group report on cleft lip and/or palate 1998, 88 .

Wolfe SA. Maxillofacial surgery: past, present and future. Plast Reconstr Surg 1993;91:1334-6.

\section{Reaction from health professionals has been muted}

EDITOR-Considering the heated exchanges in the $B M J$ in the past over the management of cleft lip and palate ${ }^{1}$ (not least an editorial $^{2}$ ), I am surprised that the importance of the long awaited report on this subject by the Clinical Standards Advisory Group ${ }^{3}$ has been largely overlooked. There seems to have been little reaction to the report from health professionals who currently work with patients with cleft lip and palate.

The $B M J$ has published a news item on the subject, but this rather missed the point. ${ }^{4}$ The report by the Clinical Standards Advisory Group focuses on far more than surgery and the (un)professional rivalry between surgical disciplines. It highlights shortcomings in the state of care of patients with cleft lip and palate as a whole and, more fundamentally, the arrangements for the delivery of that care. It raises serious concerns about auditing outcomes when most surgeons operate on under five new cases a year and estimates that only six to eight centres-out of the current 57-are truly multidisciplinary and provide good to excellent care.

In its response the government recognises that "poor clinical standards described in the study are disturbing when compared with those from other European centres" and has charged health departments to "take forward" the advisory group's specific recommendations on the concentration of expertise and resources in 8-15 centres. ${ }^{3}$ The government, at least, seems to have taken note of the fact that patients with cleft lip and palate, and their families, have been seriously let down by a system of care that in some other European countries was abandoned decades ago.

But where are the voices of health professionals who treat patients with cleft lip and palate? Is it a case that there are none so deaf as those who refuse to hear? Should they not now be supporting the government's commitment to these patients?

Some parents have telephoned this office because they are stunned by the advisory group's report. Did their children receive substandard treatment, they ask. A sense of outrage is tempered by the knowledge that the government has made a commitment to change things. But how 
quickly will things change? All those who work with patients with cleft lip and palate have a responsibility to work towards a better system of care. Parents will be proactive in pushing changes through at the greatest possible speed; will health professionals join them?

Gareth Davies Chief executive

Cleft Lip and Palate Association, London SW1W 9SA

1 Managing cleft lip and palate [letters]. BMJ 1995;311: 1431-3.

2 Markus T, Ward Booth P. Managing cleft lip and palate. BMJ 1995;311:765-6.

3 Clinical Standards Advisory Group. Cleft lip and/or palate. London: HMSO, 1998

4 Bower $\mathrm{H}$. Unpalatable results force cleft surgeons to rethink. BMJ 1998;316:723. (7 March.)

\section{Evaluating health promotion is complex}

EDIToR-The authors responding to our article on the search for evidence of effective health promotion fail to understand the complexity of evaluating health promotion. ${ }^{1}$ Britton et al acknowledge that health promotion attempts to intervene at a community or national level, but they contradict this by stating that "most health promotion interventions involve individual behaviour change." This is true of most health promotion research because behavioural interventions are conducive to experimental evaluation, unlike health goals of organisational and environmental change.

We stand by our argument that poor interventions should not be included in systematic reviews. Health promotion research does not have the benefit of studies on safety and feasibility (equivalent to phases I and II in drug development); reviewers must therefore evaluate the intervention itself. Thus interventions should be clearly and fully described and should be assessed in systematic reviews against agreed criteria, including indicators of acceptability and implementability. ${ }^{2}$

Britton et al agree that integrating evaluation methods will improve understanding of interrelations between behaviour and social structures, and the inclusion of evaluation of qualitative process will lead to a more robust evidence base for health promotion. Sheldon et al state that their reviews contain evidence from qualitative studies and that their guidelines are not prescriptive. It is unfortunate that primacy of evidence of effectiveness is afforded to findings from randomised and non-randomised controlled trials and that Sheldon et al's guidelines are widely interpreted as indicating that the randomised controlled trial is the gold standard.

The body of evidence on effective health promotion is growing, and, although limited methodologically, it is providing valuable insights into effective practice. Health promotion practitioners need not feel threatened as Sheldon et al imply. The authors' statement that "to deny the centrality of examining the effect of health promotion on health related outcomes $\ldots$ is to raise serious questions about the legitimacy of some health promotion activity" is unsupportable. There is multidisciplinary international agreement that the aims of health promotion include changing social and environmental determinants of public health and that judgment of effectiveness requires further understanding of appropriate outcome measures and research and review methodologies. ${ }^{3}{ }^{4}$ This view of health promotion is supported by the current government.

Practitioners need to develop critical, reflective practice based on evidence. We regard active discussion and critique as essential to a two way process of disseminating evidence. If, as we infer from Sheldon et al's letter, commissioners of reviews impose "gagging clauses" on those paid to disseminate findings then the process of developing sound, relevant methods and implementing them in practice will be severely hampered.

Viv Speller Senior lecturer

Wessex Institute for Health Research and Development, University of Southampton, Southampton SO16 7PX

Alyson Learmonth Director of health promotion North Durham Community Health Care Trust, Chester-le-Street, Durham DH3 3UR

Dominic Harrison Health promotion general manager

North West Lancashire Health Promotion Unit, Sharoe Green Hospital, Preston PR2 8DU

1 Search for evidence of health promotion [letters]. $B M$ J 1998:316:703-5. (28 February)

2 Flay BR. Efficacy and effectiveness trials (and other phase of research) in the development of health promotion programs. Prev Med 1986;15:451-74.

3 Meyrick J, ed. Reviews of effectiveness and their contribution to evidence based practice and purchasing in health promotion Workshop proceedings 19th March 1997. London, Health Education Authority, 1997.

4 Gemeentelijke gezondheidsdienst voor Rotterdam en omstreken. Report of the expert meeting: beyond RCT-toward evidence based public health. 13 February 1997. Rotterdam: GGD, 1997.

5 Calman K. Chief medical officer's project to strengthen the public health function in England: a report of emerging findings. Leeds: Department of Health, 1998.

\section{Older women should receive annual breast examinations}

EDITOR-Haigney et al have reported the results of a questionnaire survey of breast cancer screening practices in older women. The study emphasised the conflict between knowledge of the recommended cancer screening tests and doctors' actual practice. Some methodological aspects regarding the results were not discussed, such as the possibility of selection bias with respect to the hospital doctors interviewed (response rate $75 \%$ ). The study raises the issue that despite knowing what they should do to detect early breast cancer in elderly female patients, doctors do not provide adequate care for such patients. This could not be explained by patients' refusal to undergo a breast examination. Altogether $88 \%$ of the patients had not had mammography or a breast examination previously.

Several studies have shown that 90-99\% of women have knowledge about examining their breasts themselves. ${ }^{2}$ Only $15-40 \%$, however, perform self examination monthly, ${ }^{2}$ the frequency being lower in older age groups. ${ }^{3}$ In the United Kingdom the mortality associated with the disease in women over 70 is more than 8000 deaths/year, which corresponds to more than half of all deaths from breast cancer. ${ }^{4}$ There is no consensus regarding the benefit of annual screening mammography for women over 74 , especially because most trials have had an upper age limit of 70 . The exception is a Swedish trial that included women up to age 74 . The evidence relating to mortality among women aged 70-74, however, was inconclusive (relative risk 0.94; $95 \%$ confidence interval 0.60 to 1.64$).^{5}$ The sensitivity of mammography, clinical examination, and self examination of the breast are all higher in this age group, mainly because of liposubstitution of the breast parenchyma. Since the incidence of breast cancer is higher among this age group, the positive predictive value of these examinations is much higher. Therefore, when evaluating this population we face a conflicting situation: the incidence of cancer increases while the performance of the screening methods decreases.

Since age is the only risk factor sufficiently important to influence screening policy, older women should receive at least an annual breast examination and be instructed to perform self examination monthly. Mammography could, perhaps, be offered according to the individual risk profile. This way we might be offering more rational health care to this age group.

Rafael Marques de Souza Medical studen School of Medicine, Federal University of Rio Grande do Sul, Brazi

Valdir M de Souza Director

Sao Rafael Hospital, Novo Hamburo-RS, Brazil.

1 Haigney E, Morgan R, King D, Spencer B. Breast examinations in older women: questionnaire survey of attitudes of patients and doctors. BM 1997:315:1058-9. (25 October) OMalley MS, Fletcher SW. Screening for breast cance with breast self-ex

3 Foster RS, Constanza MC. Breast self-examination and Foster RS, Constanza MC. Breast self-examin
breast cancer survival. Cancer 1984;53;999-1005

4 Austoker J. Screening and self-examination for beast cancer. BMJ 1994;309:168-74

5 Nystrom L, Rutqvist LE, Wall S, Breast cancer screening with mammography: an overview of the Swedish randomised trials. Lancet 1993;341:973-8.

\section{Corrections}

Culyer reforms will create new opportunities for research

An editorial error occurred in this letter by Lewis (11 April 1998). The name of the author is Mark Lewis, not Clark, as published.

Doctors should beware of asking for too high a salary

An author's error occurred in this letter by P G Houghton (25 April, p 1322). The third sentence of the second paragraph talks of a consultant surgeon who had performed a prostate operating list in the morning, which had included two laryngectomies. This should have said that the surgeon performed a private operating list. 